https://doi.org/10.7250/scee.2021.0011

\title{
MODEL FOR EVALUATION OF THE SUCCESSFUL MEDICAL DEVICE PROJECT
}

\author{
Nadežda SEMJONOVA \\ Riga Technical University, Riga, Latvia \\ Corresponding author e-mail: Nadezda.Semjonova@rtu.lv
}

\begin{abstract}
General factors, determining success of the business projects, are well described both in papers and textbooks. Still, the weight and relative importance of these factors could vary significantly within the business area, moreover, in some areas, additional factors should be considered, too. The medical devices (MD) sector is a typical example: the MD market is one of the most regulated, which increases MD production costs. Another feature of the MD market is the high role of public and insurance financing. Nevertheless, small and medium enterprises (SMEs) traditionally have played a crucial role in the development of new products in the MD industry. The present paper summarizes the peculiarities of the MD market and proposes a set of parameters that could be used to estimate the success of the investment projects in the MD sector in Latvia. Besides that, the paper reviews possibilities for Latvian entrepreneurs to find financial support for implementation of medical devices projects. At the moment, Latvian Investment Development Agency and state-owned loan company ALTUM are the most promising funding sources for SMEs. On the other hand, only 13 out of 23 crediting institutions and only one leasing company out of 10 have separate programs for SMEs.
\end{abstract}

Keywords: Medical device, Model; Regulatory, Investment

JEL Classification: M21, O12

\section{INTRODUCTION}

With recent advances in medical technologies, the longevity of human life continues to grow. With such increase in proportion of older people in the society, the demand for healthcare services continues to grow, too. Alongside, limited physical activity, extended working hours, unhealthy food habits, overweight noticeably contributes to the burden of chronic diseases, provoke increase in cardiovascular heart diseases, stroke, cancer, diabetes. Need to cope with societal healthcare needs under limited resources, modern tendencies to shift the paradigm of healthcare service from hospital- based and doctor-centered toward home-based and patient-centered indicated that demand for medical devices (MD) will continue to grow, making MD sector attractive for entrepreneurs and investors. Experts (Business Research Company, 2021; Precedence Research, 2021) foresee MD sector will grow at the rate $5-6 \%$ toward 2027.

All this expands the already wide list of prerequisites for the successful implementation of a business project in MD sector. Plenty of textbooks and papers, discussing factors that contribute to the success of business projects could be found 
elsewhere, name effective project management and governance practices as the most crucial ones. The goal of the present paper is to add to these sources, outlining area specific characteristics of MD projects and to develop a model of factors for assessing the success of an MD investment project

\section{LITERATURE REVIEW}

The factors, determining success of the busines project were widely explored in literature (Pandremmenou, Sirakoulis \& Blanas, 2013; Sobieraj \& Metelski, 2021). The core of the modern project success evaluation framework, that goes back to works of Pinto and Covin (1989), includes such success factors as 1) mapping from the beginning of the project's vision; 2) the continuous support from the top management, 3) the development of detailed plans and timetables, 4) the communication between the project manager and the customer, 5) the selection of a highly skillful trained project team, 6) the use of high technology equipment in the project in terms of technical excellence, 7) the degree of acceptance of the project's deliverable to the customer, 8) the formation of control system to the process running the project, 9) The ability to manage changes, crises and deviations during the project's lifecycle. The weight and relative importance of the above factors could vary significantly in dependence of the area, where business project is implemented, and the MD sector is not an exemption.

First of all, MD market is one of the most regulated (O’Dwyer \& Cormican, 2017, Behan, Watson and Pandit, 2017). Obligation to comply with these regulations may be difficult for SMEs, especially young ones, trying to enter MD market for the first time. Provision of conformity could increase MD production costs several times, but the failure to comply with requirements would jeopardize the success if MD business project. From this point of view, mapping from the beginning of the project's vision and clear understanding of regulative processes become especially important.

Another important feature of the MD market is a high role of public and insurance financing (Mehta, 2008), that makes MD business sensitive to policies, regulating reimbursement of medical services and public procurement. In order to achieve high degree of acceptance of the project's results by the customers, continuous dialogue dialog between MD entrepreneurs, medical professionals and representatives from reimbursing structures is critical. Often, the acceptance of the product depends on whether it will become compensated by the state in the framework of medical service reimbursement scheme. The assessment of potential demand for MDs and demonstration of its efficacy for the healthcare system is impossible without estimation of social and commercial benefits of corresponding medical technologies. European Commission contributed to the harmonization of the health technology assessment methodology: the European The Regulation on health technology assessment (HTA) contributes to improving the availability of innovative technologies in the area of health, such as medicines and certain medical devices, for EU patients, it ensures efficient use of resources and strengthens the quality of HTA across the Union (European Commission, 2021).

Hidefjäll and Titkova (2015) emphasize, that MD projects often are based on prototypes developed by researchers instead of being developed on the base of thorough needs analysis followed by commercialization using clinical tests and an evolving business model to reflect learning from feedback. Instead of solely focusing on the development of the technology, MD project needs to be seen as part of a larger 
commercialization process consisting of conceptual, material and institutional development with the business model design in focus to meet healthcare system requirements.

StarFish (2021), being leading Canada's MD design service provider with a full complement of design, development, and manufacturing services, provides a guideline for MD development, that involves series of stages, that ensure a smooth transition from product definition and proof of concept through quality management, clinical trial and, finally, approval by national health authorities. Note, that timeline of MD project should include post-market support: following EU regulation, member state should provide MD vigilance system. For instance, in Latvia, MD manufacturer or distributor should collect "vigilance incident report" on any incidents or potential incident related to the use of a MD that has resulted in or may result in death or serious harm to the health of a patient, user or third person. Simultaneously, the vigilance repost should be submitted to the State Agency of Medicines (ZVA, 2021).

Another example of framework for the development of MD projects is peovided by Japan Agency of Medical Research and Development (AMED, 2021). The Agency promotes collaborative networks between the national government and local regions so that medical device developers, including newcomers, can receive various support including pharmaceutical affairs, intellectual property, technology, and marketing in an integrated manner. This work aims at autonomous progress of development/ commercialization of medical devices through collaboration between medicine and engineering.

Valla (2019) notes, that for MD sector, an effective strategy to minimize residual risk is achieved by combining quality management and risk management processes and implementing them as early as possible in the course of project implementation.

Maresova et al. (2020) pay special attention to the need to conduct fairly accurate calculations of project costs and the assessment of an investment project.

Small and medium enterprises (SMEs) have traditionally played a crucial role in the development of new products in MD industry. SMEs are able quickly adapt to new market niches and poses considerable innovative potential. In recent decades, SMEs contributes to the development of more than $50 \%$ of all innovative MD products (Medical Device Network, 2010). Hereby, MD market seems to be a promising option for SMEs business development. But SMEs could meet difficulties in the selection of a highly skillful trained project team just because of limited resources. Thus, the individual qualification and skills of team members are more important in the case id SMEs.

\section{METHODOLOGY}

The study design is based on two stages. The first stage analyses the literature to assess the success of the project to develop a model for assessing the successful MD of the project.

The second stage is an analysis of Latvia's electronic resources to develop a model for attracting external financing for CME.

To determine the SME lending facility, 23 offers from banks and credit companies were analyzed using data from Finance Latvia Association (FLA, 2021) and The Financial and Capital Market Commission (FKTK, 2021). 10 leasing companies were 
evaluated for the analysis of SME machinery and equipment leasing opportunities, using data from Latvian Leasing association (LLDA, 2021).

\section{RESULTS}

\subsection{Model of the successful Medical Device project development}

The indicator of success has a social aspect, it contains the subject of social approval. In project activities, a distinction is made between the success of the project and the success of project management. The success of the project characterizes the properties, timeliness and public perception of the project product, and the success of project management is the observance of the agreed parameters of project activities, professionalism and coherence of the project team.

Figure 1 summaries the most important factors, critical for the implementation of the MD business project. Since the industry is very highly regulated, it is necessary to constantly monitor changes in regulations in a particular country. Some restrictions may apply only to a certain class of MD. This will be very important for the successful management and completion of the project, which is why this is indicated in the model as the first item.
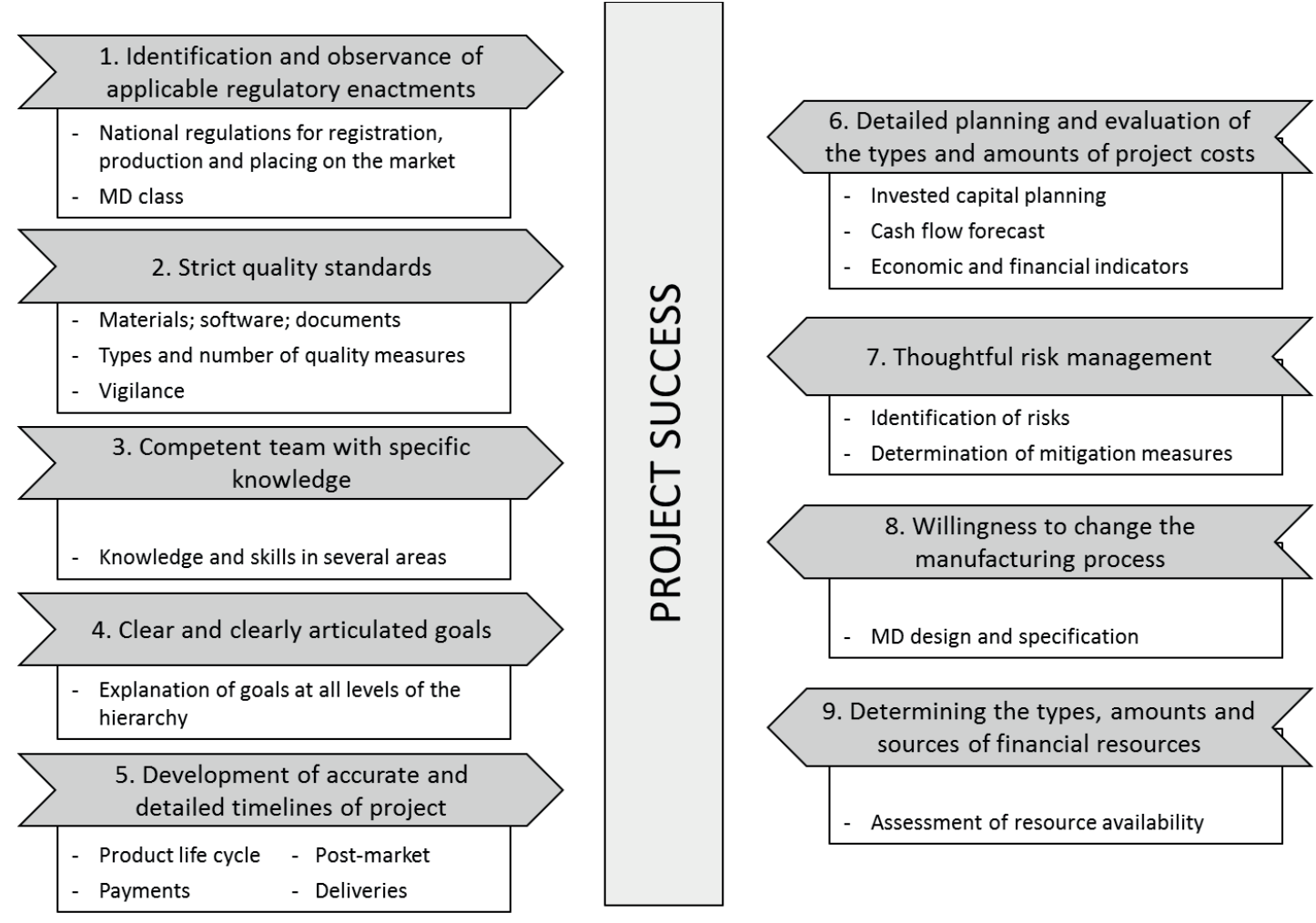

Fig. 1. Model of the successful Medical Device project

The special attention should be paid to the need to conduct fairly accurate calculations of project costs and the assessment of an investment project. Various indicators described by Maresova et al. are used here (Maresova et al., 2020).

When planning the cash flow, one should consider that the MD turnover on the market will be longer than its life cycle, at least for the warranty period. Even if the 
enterprise has ceased to produce this type of MD, the costs continue to form because of post-market activities and vigilance system support.

The connecting link of all factors is the team that implements the investment project. The complexity of the situation lies in the fact that workers in SMEs in this industry must have knowledge in medicine, engineering, finance, and management. This could comprise a problem since education system still has some shortage in offering such comprehensive and multidisciplinary courses.

\subsection{SME financing opportunities in Latvia}

Despite there are many platforms in the world that support SMEs, the unawareness on possible funding sources and lack of financial skills make difficult development of small and medium enterprises in MD industry sector in Latvia.

Medical device innovations have been developed by a mix of private and public funding. The largest financial instruments within the framework of which Latvia receives financial assistance are the EU funds: European Regional Development Fund (ERDF), European Social Fund (ESF) and Cohesion Fund (CF), their management in Latvia is provided by the Ministry of Finance.

At the early stage of the MD development, EU funds resources could be used, although with a relatively low success rate. Alongside, one has to keep in mind that use of EU funds is possible only in cooperation with the universities.

More easily entrepreneurs could be supported by Latvian Investment Development Agency (LIAA). LIAA offers support to entrepreneurs who are looking for markets abroad and invites them to use the services offered by the agency - to establish new contacts in trade missions, national stands, contact exchanges, individual visits and to attend export seminars. One of the priorities of LIAA is to turn the results of the work of scientific institutions into commercially successful projects and to attract entrepreneurs to innovations (LIAA, 2021).

ALTUM is a state-owned development finance institution, which offers state aid for various target groups with the help of financial tools (such as loans, credit guarantees, investing in venture capital funds, etc.) (ALTUM, 2021).

It can be seen from the scheme (see Fig.2.) that the state-owned company Altum combines the offers of the public and private sectors as a result of extensive cooperation.

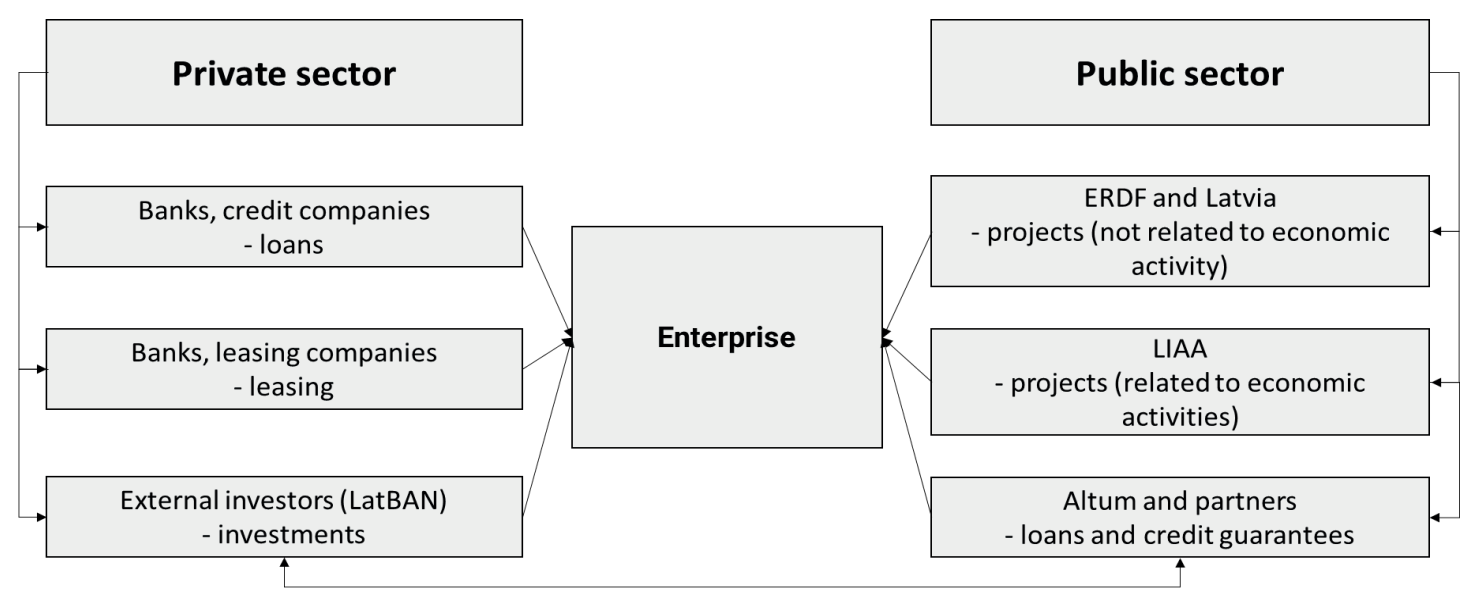

Fig. 2. SME external financing model in Latvia 
Latvian Business Angel Network (LatBAN) is the association with the goal of the association is to extend and develop the network of investors in Latvia and support new and perspective projects. This is why we organize Investment Sessions, during which investors and new entrepreneurs meet with each other (LatBAN, 2021).

Out of 23 credit institutions, only 13 have separate programs for SMEs (FLA, FCMC, 2021) and only 1 leasing company out of 10 has an offer for SMEs (LLDA, 2021). However, this does not mean that resources are not available, it is just that the contracts will be concluded on general terms.

\section{CONCLUSION}

The presented model represents set of factors that could be used to characterize the success of the investment project on the medical device market. It can serve as a foundation for the preparation, evaluation, and implementation of MD investment projects. The investor should take into account the main peculiarities of MD sector projects: first, the need for continuous monitoring and adaptation to the changes in regulative acts and, second, extended requirements for the post - market stage, when manufacturer has to follow up the performance of the devices in the framework of vigilance system.

The external financing model gives an idea of the company's ability to increase its financial capabilities. In Latvia, the possibilities for SMEs to get support for research and development of entirely new MD technology is limited to university - affiliated scientific projects, that usually has low success rate. Form the other hand, there is more possibilities to attract funding, both private and governmental, for the projects at the higher technology readiness levels, when technology already was demonstrated as feasible.

\section{ACKNOWLEDGMENT}

This work has been supported by the European Regional Development Fund within the Activity 1.1.1.2 "Post-doctoral Research Aid" of the Specific Aid Objective 1.1.1 "To increase the research and innovative capacity of scientific institutions of Latvia and the ability to attract external financing, investing in human resources and infrastructure" of the Operational Programme "Growth and Employment" No.1.1.1.2/VIAA/2/18/343 The methodology for the commercialization of innovative biomedical devices and the evaluation of the productions financing model.

\section{REFERENCES}

Altum. (2021). Services Retrieved from https://www.altum.lv/en/services

AMED. (2021). The development / commercialization programs. Retrieved from https://www.amed.go.jp/en/program/list/02/01/006.html

Behan, R., Watson, M., \& Pandit, A. (2017). New EU medical device regulations: Impact on the MedTech sector Medical Writing, 26(2), 20-24.

Business Research Company (2021) Medical Devices Market. Retrieved from https://www.thebusinessre--* searchcompa-ny.com/report/medical-devices-market

Guerrero J.C., García J.H., Hernández A.M. (2017) Study of Medical Device Purchasing Cycles through Temporal Series Analysis. In: Torres I., Bustamante J., Sierra D. (eds) VII Latin American Congress on Biomedical Engineering CLAIB 2016, Bucaramanga, Santander, Colombia, October 26th -28th, 2016. IFMBE Proceedings, vol 60. Springer, Singapore. https://doi.org/10.1007/978-981-10-40863119

EU funds. (2021). General Information. Retrieved from https://www.esfondi.lv/general-information-1 
European Commission (2021) Regulation on Health Technology Assessment Retrieved from https://ec.europa.eu/health/technology_assessment/eu_cooperation_en

FKTK. (2021). Market Retrieved from https://www.fktk./v/en/market/

FLA. (2021). Industry data. Retrieved from https://www.financelatvia.eu/en/

Hidefjäll, P., \& Titkova, D. (2015). Business model design for a wearable biofeedback system. Studies in Health Technology and Informatics, 211, 213-24. https://doi.org/10.3233/978-1-61499-516-6-213

LatBAN. (2021). Do you have a business project that needs an investor - business angel? Retrieved from https://latban.lv/en/projects

LIAA. (2021). Invest in Latvia. Retrieved from https://www.liaa.gov.lv/en

LLDA. (2021). About us. News. Retrieved from http://www.llda.lv/en/?menu_id=310

Marešová, P.; Peter, L.; Honegr, J.; Režný, L.; Penhaker, M.; Augustýnek, M.; Mohelská, H.; Klímová, B.; Kuča, K. Complexity (2020). Stage Model of the Medical Device Development Based on Economic Evaluation-MedDee. Sustainability, 12, 1755. https://doi.org/10.3390/su12051755

Medical Device Network. (2010). Small Businesses have Big Impact on Device Market. Retrieved from https://www.medicaldevice-network.com/features/feature73715/

Mehta, S. (2008). Commercializing Successful Biomedical Technologies: Basic Principles for the Development of Drugs, Diagnostics and Devices. Cambridge University Press. https://doi.org/10.1017/CBO9780511791345

O’Dwyer, C., \& Cormican, K. (2017). Regulation - Do or Die: An Analysis of Factors Critical to New Product Development in a Regulatory Context. Journal of Technology Management \&Amp; Innovation, 12(1), 26-38. https://doi.org/10.4067/S0718-27242017000100004

StarFish. (2021). Five Steps to Medical Device Development Success. Retrieved from https://starfishmedical.com/blog/beta-medical-device/

Valla, V. (2019). Impact of Design on Medical Device Safety. Therapeutic Innovation and Regulatory Science. 54(4), 1-11. https://doi.org/1-11. 10.1007/s43441-019-00022-4

ZVA. (2021). Medical devices Retrieved from https://www.zva.gov.lv/en/healthcare-professionals-andinstitutions/medical-devices

\section{AUTHORS' SHORT BIOGRAPHY}

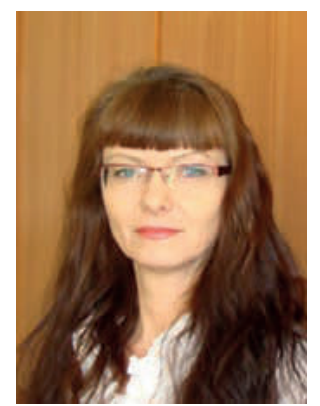

Nadezhda Semjonova graduated from the Faculty of Engineering Economics and Management of the Riga Technical University in 1993 (Bachelor of Busines Administration) and in 1997 (Master of Busines administration). She received the $\mathrm{PhD}$ in Economics from the Riga Technical university in 2015. Her thesis topic was the modelling of the government debt policy.

She is Senior researcher at the Department of Corporate Finance and Economics since 2018, docent at the Department of Corporate Finance and Economics since 2015, lecturer at RTU from 2000.

Scientific interests: state finances, government debt management, medical device market research.

E-mail: Nadezda.Semjonova@rtu.lv

ORCID ID: http://orcid.org/0000-0002-8168-324X 